\title{
Building a Culture of Academic Integrity in the Student Environment Case of Vinnytsia National Technical University (Ukraine)
}

\author{
Iryna Drach, Olena Slobodianiuk
}

Institute of Higher Education of the National Academy of Educational Sciences, Kyiv, Ukraine

Email: i.drach@ihed.org.ua, lenaslobodianuk1970@gmail.com

How to cite this paper: Drach, I., \& Slobodianiuk, O. (2020). Building a Culture of Academic Integrity in the Student Environment Case of Vinnytsia National Technical University (Ukraine). Creative Education, 11, 1442-1461.

https://doi.org/10.4236/ce.2020.118105

Received: July 31, 2020

Accepted: August 24, 2020

Published: August 27, 2020

Copyright $\odot 2020$ by author(s) and Scientific Research Publishing Inc. This work is licensed under the Creative Commons Attribution International License (CC BY 4.0).

http://creativecommons.org/licenses/by/4.0/

(c) (i) Open Access

\begin{abstract}
Since Ukraine has declared its intention to reform higher education aligned with the European standards, it has been stated that quality assurance of education in the European Higher Education Area (EHEA) is one of the main conditions for trust, mobility, motivation, compatibility and attractiveness of higher education. One of the key components for the internal quality assurance system in the higher education institutions (HEI) is the establishment of the system of academic integrity at the institutional level allowing creation of a zero environment of tolerance to violations of academic integrity and ethics of academic relations; this justifies the relevance of the article. The aim of the article is to analyze Vinnytsia National Technical University (VNTU) experience in implementing the project "Building a culture of academic integrity in the student environment". The project has been implemented within the framework of the Ukraine Higher Education Leadership Development Programme. To achieve this aim, methods of analysis, synthesis, comparison and systematization of a set of actions contributing to the project implementation have been used. The outcomes of the project have been described and it has been established that the implementation of policies and mechanisms to ensure academic integrity in teaching, learning and research needs to be shifted from penalty for violation of academic integrity to planning and implementing explanatory and educational activities. Steps for further development of the culture of academic integrity in VNTU have been outlined.
\end{abstract}

\section{Keywords}

Academic Integrity, Ensuring Academic Integrity Higher Education, Principles of Academic Integrity 


\section{Introduction}

The late 20th and early 21st centuries are known for their radical transformations of the higher education system. "[...] Change of the forces influencing modern higher education around the world have led to increasing and strengthening factors affecting it" (Becher \& Trowler, 2001), namely: a radical increase in the number of student population; economization of academic area leads to an increase in the impact of applicants and students' demands and needs concerning the content and practical orientation of programs and courses; globalization leading to a focus on global economic trends, rapid development of new information and communication technologies, creation of an international knowledge network, use of English as the dominant language in disseminating scientific information (Altbach, Reisberg, \& Rumbley, 2009). This, in turn, constantly stimulates the ongoing growth of social and professional mobility of an increasing part of the population, greater diversification of higher education systems in most countries, new forms of scientific knowledge production, ever-increasing value of problem-oriented knowledge, its transdisciplinary nature.

A problem of quality assurance and enhancement of higher education has been actualized through the intensive transformation processes. Schleicher warns " $[. .$.$] without proper education, people will wander on the margins of so-$ ciety, and countries will not be able to take advantage of technological advances for the sake of progress" (Schleicher, 2018: p. 15). Therefore, in the context of the higher education system reforming, a quality enhancement is one of the top priorities. Having chosen the European vector for development, our state should focus on the best examples of the quality culture of education. Quality is a key precondition for trust, compliance, mobility, compatibility and attractiveness in the EHEA. "Concern for quality should become an imperative for the behavior of all those caring of the academic world" (Hrynevych, 2014: p. 12).

In recent years, Ukraine has taken significant steps to create a legal basis for the implementation of quality assurance in higher education: the Law of Ukraine "On Education" (2017), the Law of Ukraine "On Higher Education" (2014), the Law of Ukraine "On Copyright and Related Rights" (2015), the National Strategy for the Development of Education in Ukraine for a period up to 2021 (2013) have been adopted. The National Agency for Quality Assurance in Higher Education has been launched. One of the tools for obtaining high quality higher education, which involves increasing the intellectual capital of a learner, is to follow the principles of academic integrity.

The adoption of the Bucharest Declaration concerning ethical values and principles of higher education in the Europe Region (The Bucharest Declaration Concerning Ethical Values and Principles for Higher Education in the Europe Region, 2004) witnessed the importance of the ethical dimension in the process of profound transformation of higher education. The section "Values and Principles" of the document clearly defined the role of academic ethos, culture and community, academic integrity in the teaching and learning processes, democratic and ethical leadership and management, research based on academic inte- 
grity and social responsibility (The Bucharest Declaration Concerning Ethical Values and Principles for Higher Education in the Europe Region, 2004). The International Center for Academic Integrity at the Rutland Institute for Ethics at Clemson University (South Carolina, USA) has developed the document "Fundamental Values of Academic Integrity", according to which academic integrity is commitment of the academic community to six fundamental values: honesty, trust, justice, respect, responsibility and courage (Fishman, 2013).

There is an interest in solving the problem of ensuring academic integrity in HEIs in Ukraine. For example, among forty Ukrainian universities that participated in the "Leadership Development Program of Ukrainian Universities" organized by the British Council in Ukraine in the partnership with the Institute of Higher Education of the National Academy of Educational Sciences of Ukraine, supported by the Ministry of Education and Science of Ukraine (2016-2019) (hereinafter-Program), three universities chose the topic of ensuring academic integrity, namely Kyiv National Economic University named after Vadym Hetman, Chernihiv National University of Technology and Vinnytsia National Technical University.

In VNTU the project "Building a culture of academic integrity in the student environment" (hereinafter-the Project) ran in 2018-2019. The project aimed to implement the objectives formulated in the Development Strategy of VNTU for the period 2018-2023 and the Regulations on the organization of the educational process in VNTU. VNTU Development Strategy for the period 2018-2023 provides "establishing corporate culture of the university through the development of moral, cultural and scientific values", "expanding the range of educational services focused on the needs of socio-economic development of the region" (VNTU Development Strategy for 2018-2023). The Regulations on the organization of the educational process at VNTU emphasize the need to "establish, preserve and increase moral, cultural, scientific values in the educational process by all participants" (Regulations on the organization of the educational process at VNTU? 2017).

The aim of the Project was to promote the principles and culture of academic integrity among students as a basis for honest intellectual work, their awareness of the relationship between academic integrity as a tool for quality education and successful professional careers.

The aim of the article is to analyze the experience of Vinnytsia National Technical University in the implementation of the project "Building a culture of academic integrity in the student environment".

The task of the article is to characterize the results of the Project implementation; to reveal the influence of the "Leadership Development Program of the Universities of Ukraine" on the implementation of the Project; to outline steps for further development of the academic integrity culture in VNTU.

\section{Research Methods}

In order to study the attitude of students to issues of academic integrity, the au- 
thors of the article conducted sociological survey among students of 1 (445 students, 2018) and 3 (390 students, 2020) courses in VNTU of all faculties, namely: at the faculty of computer control systems and automation, at the faculty of civil engineering, Faculty of Energy, Ecology and electromechanics, information faculty Technologies and computer engineering, faculty Mechanical Engineering and Transport, Faculty Radio engineering, telecommunications and electronics Instrument making, faculty of management and information security. The results of the survey will help to develop and approve guidelines for administrative and teaching staff on the use of tools to implement and maintain the principles of academic integrity (at the faculty, department, study group); instructional materials for teaching and support staff of VNTU to promote the development and prevention of violations of academic integrity.

Methods of analysis, synthesis, comparison and systematization of a set of activities that contributed to the project have been used. The method of generalization made it possible to draw conclusions about the outcomes of the study and offer recommendations for HEIs to ensure the principles of academic integrity.

\section{Results of Research and Discussion}

The Law of Ukraine "On Education" (2017) laid the foundations for the development of academic integrity in the Ukrainian higher education institutions, which, along with the possibility to build university autonomy aligned with the Law "On Higher Education” (2014), allows establishing real mechanisms for academic integrity in universities.

According to the results of a sociological survey on VNTU students' awareness of the need to follow the principles of academic integrity and the inadmissibility of fraud (September 2017), the motivation of a large part of students is aimed at formal attributes of higher education (grades, scholarships, diplomas, etc.). Thus, it was found that $69 \%$ of students are involved in dishonest academic practices when taking exams; more than $75 \%$ of students use plagiarism in one form or another; $43 \%$ of students cheat on exams. At the same time, students consider the following priority actions to be taken to improve the quality of education: establishing cooperation with the world's best universities (43\%); connecting teaching with the needs of the future profession (36\%); fighting against all manifestations of corruption and dishonesty (44\%). The results of the survey allowed concluding that existing regulatory framework (Code of Ethics of VNTU; Regulations on the detection and prevention of academic plagiarism in VNTU) is a necessary but insufficient condition for implementing the principles of academic integrity in student environment.

Thus, ensuring the strategic priority of the university (development of personality on a value-oriented basis), increasing its social role in the region, as well as the results of the survey led to the urgency of the problem to adhere to the principles of academic integrity in the student environment. In 2017, it was decided to develop a project "Building a culture of academic integrity in the student environment of VNTU" (hereinafter-the Project) and create a team for its im- 
plementation. The main objectives of the Project were as follows: educating moral and ethical values in students; providing a wide range of motivation for students to honest and responsible learning; changing the attitude of students, scientists and academics to violations of the principles of academic integrity.

A key factor for achieving this goal was the participation of the VNTU team in the Program (2018-2019), which provided the following: 1) support to leadership development as a critical tool for promoting institutional and sectoral changes; 2) involvement of the next generation leaders in initiatives together with those occupying leadership positions; 3) students' involvement in management (Ukraine Higher Education Leadership Development Programme: Impact Report, 2019: p. 8).

Since the task of the article does not include a detailed analysis of the content and outcomes of the Program (see more about this: (Kalashnikova \& Prokhor, 2017; Ukraine Higher Education Leadership Development Programme: Impact Report, 2019; Kalashnikova \& Orzhel, 2019)), we note only that: "the change agents and pool of expertise developed by the Programm are a resource that has the potential to make an important contribution to developing sector policy and practice in these areas. The Programm selected university teams with the capacity and readiness to drive higher education change and equipped them with change leadership knowledge, skills and practice. By disseminating their learning to other universities, the aim was that they would generate momentum for wider institutional change and build critical mass for system change" (Ukraine Higher Education Leadership Development Programme: Impact Report, 2019: p. 33).

Achieving the main goal of the Program (to develop a national cohort of change agents with the leadership skills to drive institutional and sector change) required an unconventional approach to project teams, which should include representatives of each university unit, including students in particular. According to the authors of the Program, establishing a new culture of cooperation among representatives of the university units (administration, research and teaching staff, students) should be based on the distributed leadership concept by university teams. Such approaches to the creation and operation of university teams were aimed at strengthening partnership, openness, transparency, awareness of the distributed responsibility importance, which, in turn, should contribute to establishing sense of unity and cohesion in institutional development.

The VNTU team was headed by the rector of VNTU Hrabko. This was an important feature testifying the support of ideas and awareness of the importance of the Project implementation at the highest level of university management.

The program included two sessions for participants of the "Team Leadership" component.

The first session, "The Team Development Center", provided an opportunity for the teams to get to know the concept of the Program, to establish a network of contacts with representatives of other HEIs. During the first session, members of the VNTU team learned the modeling of approaches to interaction, team pro- 
file and the role of each participant in teamwork on the basis of distributed leadership. It was important for the Project implementation to realize that a positive outcome requires strategic planning, and the tools of system analyses such as PESTLE-analysis and SWOT-analysis became useful for assessing the position of the institution, its potential and focused activity.

The second session, "Academy of Change", provided the following steps: to detail the Project plan, provide tools and mechanisms for the implementation of strategically important changes in the university, to develop creative and critical thinking. One of the key points of the session was the task to map stakeholders. Subsequently, in the course of the Project implementation, careful elaboration of the list of potential external and internal stakeholders (through a combination of indicators of power and interest) contributed to the expansion of their circle. Individual stakeholders (group curators, heads of departments, representatives of the region's business elite, etc.) as well as representatives of state (Vinnytsia City Council, Institute of Urban Development) and public (HUB City of Contents, Public Initiatives of Ukraine) were additionally identified as stakeholders organizations. It should be noted that expansion of the list of stakeholders not only contributed to the implementation of this project, but also became a catalyst for planning and implementing other projects important for the development of the institutional capacity of the university.

These sessions greatly changed all team members' understanding concerning management in a modern university. Gradually (and not easily) the awareness of the need to strengthen horizontal ties; expand involvement of external and internal stakeholders in the management; take into account "voice of students" in the discussion of university prospects; focus on professional and personal development of academics have crystallized. In particular, learning of the theoretical positions and intensive trainings formed understanding that:

- teamwork on the basis of leadership will promote the ideas of the Project in the university; partnership, responsibility and mutual assistance should become a tool to increase a number of those who, by joining team members, will become like-minded in the process of establishing a culture of academic integrity in the student environment;

- systematic detailed analysis of project activities will allow additional review of ideas, concepts, tools of the Program for the implementation of changes in the university (in management, development of student-teacher relations, university administration-student self-government body relations);

- knowledge and experience gained during the session of the Program will allow scaling the innovative approach to the formation of any team in order to implement changes in the university.

As mentioned above, the implementation of the Project was clearly aligned with the Development Strategy of VNTU for the period 2018-2023. The purpose and objectives of the Project, available resources of the institution for its implementation determined a set of actions at each stage: preparatory; implementation, monitoring the outcomes on culture of academic integrity in the student 
environment in VNTU.

It was assumed that indicators of positive change should be:

1) Increasing the number of students who have a negative attitude to violations of academic integrity (academic plagiarism, self-plagiarism, fabrication, falsification, cheating on exam, deception, bribery, biased evaluation).

2) Reducing the number of violations of academic integrity among students.

3) Increasing the quality of graduation and research papers submitted to the All-Ukrainian competition of student research papers.

Let's move on to the analysis of the project implementation. Activities to promote the values of academic integrity were launched by team members in late 2017. The tasks of the preparatory stage included:

- learn, evaluate and analyze the possibility of adapting foreign experience in the implementation of the principles of academic integrity in VNTU;

- learn the experience of Ukrainian universities in promoting academic values;

- do research concerning the culture of academic integrity formed in the educational environment in VNTU.

The academics were to become key subjects of the outlined tasks as they, first of all, should not only follow the principles of academic integrity, but also influence their observance by students. To obtain empirical data on academics' understanding of academic integrity importance an anonymous survey was conducted (May 2018). 58 academics of VNTU were involved. A detailed analysis of the study has been presented in the article "The role of academics in the establishment of academic integrity among students" (Slobodianiuk, 2018). The results suggest that, firstly, academics are not aware of the logical link between violations of academic integrity and the quality of education and, as a consequence, learning outcomes. Secondly, the practice of academics' activity in VNTU allows stating the lack of systematic control over plagiarism in works for intermediate control (abstracts, essays, coursework, etc.), which can lead to borrowing ideas in course and diploma projects (works). If plagiarism is detected in students' written work, "soft penalty" is usually taken against violators: returning the work to the student and crediting the corrected work after re-submission, oral remarks. It creates grounds for students not to treat plagiarism as a crime.

This situation suggests that the need to follow the principles of academic integrity by students is defined at the national level (Law of Ukraine "On Education", Article 42, paragraph 2, Law of Ukraine "On Amendments to Certain Laws of Ukraine to Improve Education Activity in Higher Education") and at the institutional level (Regulations on the detection and prevention of academic plagiarism in VNTU), at the same time, as the "survival" of the university depends on the number of students, strict penalty against violators of academic integrity is not used. As a result, the desire to circumvent regulatory requirements becomes the norm for administration (deans, heads of departments, etc.) academics, and students.

As a part of the Project, an expanded and deeper study (compared to the 2017 
survey) on students' attitude toward academic integrity through a survey (May 2018) was conducted. There were 445 respondents.

The results of the survey testified to the urgency of the problem of forming the motivational and value component of the culture of academic integrity in students and the development of awareness that learning outcomes should be professional and social competencies acquired through systematic honest work. These surveys confirmed the need to create an effective mechanism for the interaction of HEIs with representatives of the labor market. Close cooperation and feedback from employers should help students realize that quality professional knowledge is the key to employment and the basis of a strategy for success in life in general.

Analysis of students' responses concerning the practice of organizing and passing tests and exams allowed us to conclude that to reconcile the collective/university interests (reputation, image, rating, etc.) and individual students' interests (quality educational services, social skills, partnership relations with academics, etc.) should be guided by common values, described in the regulations of VNTU (Code of Honor of VNTU, Regulations on Academic Integrity, etc.). Academics should not only show excellent examples of intellectual work, but also accompany and advise students on the need (moral, legal, social, etc.) to follow the principles of academic integrity.

The results of students' responses concerning the understanding of the concept of "plagiarism" and their attitude to it showed that there is an urgent need to update the content of education by adding the discipline "Academic Writing", as well as reviewing number, content and forms of written works. The need to intensify efforts to systematically check students' written works for plagiarism proved to be critical.

Thus, summarizing the obtained results give us grounds to state the validity of B. Gallant's opinion that in the 21st century the teacher should focus not on how to prevent deception, but on how to encourage students to learn (Gallant, 2012).

Taking into account the results of the study and understanding the "foundation of knowledge, skills and experience of change management" (Leadership Development Program of Ukrainian Universities: Impact Assessment, 2019: 34), acquired during two sessions of the Program, team members began the direct implementation of the Project which foresaw a range of activities (Table 1).

The implementation of the Project revealed a number of challenges were not expected by the team, in particular, at the beginning of the distrust and indifference of the University Academic Council members to the efforts of the team. Due to the systemic problem of ensuring the principles of academic integrity, its solution required the unification of all participants in the educational process, including members of the Academic Council, whose authority in VNTU is undeniable. Therefore, involving leading scholars in activities to improve a culture of academic integrity has become a priority for the team. This was the important thing able to strengthen the university's ability to make changes at the level of faculties and departments. 
Table 1. A set of actions to implement the principles of academic integrity in VNTU.

\begin{tabular}{|c|c|}
\hline Areas of activity & Actions \\
\hline $\begin{array}{l}\text { Development of value } \\
\text { orientations and motivation to } \\
\text { follow the principles of } \\
\text { academic integrity }\end{array}$ & $\begin{array}{l}\text { - conducting a series of trainings for academics and students: } \\
\text { - Academic integrity: the essence and regulatory support"; } \\
\text { - Culture of academic integrity as a component of the academic } \\
\text { culture of the university; } \\
\text { - "Tools for the prevention of violations of academic integrity"; } \\
\text { - "Academic integrity and professional success"; } \\
\text { - conducting Debate tournaments and quests "Principles of } \\
\text { academic integrity-our choice" for the first-year students of all } \\
\text { faculties; } \\
\text { - conducting a series of student meetings with successful } \\
\text { businessmen, authors of innovative startups to study the } \\
\text { experience and factors of a successful career; } \\
\text { - conducting a simulation game "Interview: an opportunity not } \\
\text { lost" in the framework of "Career Days". }\end{array}$ \\
\hline $\begin{array}{l}\text { Design of normative documents } \\
\text { and information support of the } \\
\text { Project implementation }\end{array}$ & $\begin{array}{l}\text { - development, discussion and approval of the "Code of academic } \\
\text { integrity of VNTU students"; } \\
\text { - creating a page on the website of VNTU and a group on } \\
\text { Facebook to involve students in discussions, providing } \\
\text { proposals within the project activities; } \\
\text { - creation of a site on the page of the scientific and technical } \\
\text { library of VNTU "To assist a scientist" to help in research } \\
\text { activities; } \\
\text { - expansion of cooperation with representatives of the online } \\
\text { service Unicheck Ukraine. }\end{array}$ \\
\hline $\begin{array}{l}\text { Modernization of the } \\
\text { organizational structure of the } \\
\text { university and updating the } \\
\text { content of education }\end{array}$ & $\begin{array}{l}\text { - establishment of an Academic Integrity Advisory Center to } \\
\text { prevent plagiarism; } \\
\text { - creation and launch of a repository of bachelor's and master's } \\
\text { theses of VNTU students to combat student plagiarism; } \\
\text { - development and inclusion of the module "Principles of } \\
\text { Academic Integrity" in the discipline "Introduction to the } \\
\text { specialty" for the first-year students and the module "Culture of } \\
\text { Academic Integrity" in the discipline "Fundamentals of } \\
\text { Research" for master students. }\end{array}$ \\
\hline
\end{tabular}

To clarify the researchers' awareness of the relationship between the concepts of "university competitiveness" and "culture of academic integrity", their attitude to non-compliance with the principles of academic integrity, their trust in team members and willingness to contribute to the Project the team conducted a survey among members of the Academic Council (48 out of 80 representatives of the collegial governing body of the university agreed to answer the questions).

$78 \%$ of respondents gave an affirmative answer to the question "Will raising the level of culture of academic integrity in VNTU contribute to the growth of the university's competitiveness?" This is evidence of a conscious position concerning the relevance of establishing a culture of academic integrity. Among the list of violations of academic integrity (cheating on exams, plagiarism, fabrication, falsification, bribery, etc.), $88 \%$ of respondents named bribery as one that should be combated as the first violation.

Despite the fact that $67 \%$ of respondents answered "yes" (24\%- "difficult to 
answer", 8\%- "no") the question "Will the implementation of the Project to implement the principles of academic integrity in the university", i.e. two thirds of the Academic Council members were aware of the importance of the project for establishing a culture of academic integrity in the student environment, the team's cooperation with the Academic Council was difficult to call constructive because, in our opinion, conservatism and traditionalism of most of its representatives and lack of communication connections in the university environment.

The complexity in disseminating information prompted us to search additional resources. Creation of an initiative group (which included curators of academic groups, employees of the scientific and technical library, academics of the department of integration of training with production, etc.), use of information base (official site of VNTU, press center of VNTU, columns of the magazine "Impulse", scientific technical library of VNTU, etc.) contributed to the expansion of the communication base for promoting the ideas of the Project: from comprehension of the moral norms and academic values, creation conditions for the restructuring of relations (teacher-student, teacher-administration, students-administration) to the choice of honest means and technologies for acquiring new knowledge, registration of research results. In addition, in order to inform the University Academic Council members about the qualitative changes taking place in the University due to the implementation of the Project, the team members launched open reports at its meetings.

It should be noted, that during the Project team members developed an understanding of the importance for improvement of the academics' professional and pedagogical competences and creation of a modern spatial and subject environment being different from the existing interior design of university classrooms.

It should be noted that for a long time there was no professional discussion at VNTU on the modernization of the model for academics' professional and pedagogical competence development. As the system of teacher evaluation was focused on quantitative indicators of research activity (number of publications, publications in scientometric databases) and did not take into account the level of direct teaching, it contributed to their use of outdated disciplines, passive teaching methods and non-transparent evaluation principles and criteria, insufficient teachers' mastery of tools to motivate students. To increase the level of professional and pedagogical competence of academics, in January 2020 VNTU introduced advanced training under the program "Development of professional and pedagogical competence of academics of Vinnytsia National Technical University".

An important condition for the process of establishing a culture of academic integrity in the student environment, according to team members, was to stimulate cognitive activity of students. This is ensured, in particular, by the use of interactive forms and methods of teaching in a modern spatial and educational environment, which should be multifunctional, equipped with multimedia and 
easily transformed furniture. The informal atmosphere of modern spatial solutions sets up sincere open communication. At the initiative of team members and thanks to the support of the administration a Training Center was opened in VNTU. Now it is the space where most of the planned activities of the project (trainings, debate tournaments, co-working, etc.) take place, as well as the educational process of students and academics' professional development.

The implementation of the Project provided learning the international experience how the principles of academic integrity in the university environment are followed. To learn the international experience the VNTU team visited the University of Northumbria at Newcastle (UK). Since the high quality of higher education in the UK is confirmed by the position of HEIs in international university rankings, a visit to British university was very important for the team.

The visit took place in October 2018 with the assistance of the British Council in Ukraine and the Dean of the Department of Entrepreneurship, Innovation and Strategy, the Faculty of Business and Law at the University of Northumbria at Newcastle Mordue. Baranchenko, Senior Lecturer of the Department of Entrepreneurship, Innovation and Strategy, Faculty of Business and Law, accompanied the team during the visit.

The main purpose of the VNTU team's visit was to study the practices of the University of Northumbria concerning the support of academic integrity as a fundamental value of the educational community, prevention of violations of the principles of academic integrity, and building a system of academic integrity at the institutional level.

During the meetings with the VNTU team, Mordue described the role of teachers in creating an atmosphere at the university that would promote the recognition of such values as honesty, trust, responsibility, respect. Petts focused on the problem of plagiarism; software for detecting plagiarism and mistakes in students' written works (Turnitin, Grammarly, iThenticate). The scientist stressed that he considers plagiarism to be a problem, first of all, legal, as companies (for example, the famous Edu Birdie) operate freely, which openly offer turnkey written works and undermine the system of quality education. Arakpogun focused on activities aimed at establishing a culture of academic integrity in the student environment. The policy, practice and processes of ensuring academic integrity at the university are aimed at forming a sense of belonging to the academic community, respect for generally accepted norms and principles of teaching.

The main result of this visit was the intensification of the team's initiatives to create conditions for establishing a corporate culture of VNTU, the value component of which is academic integrity. The team members made changes to the planned activities of the Project, namely: to prepare speakers representing student self-government body to promote the ideas of the Project; to develop and implement a training module "Principles of Academic Integrity" for the discipline "Introduction to the specialty" (for the first-year students) and offer a discipline on students' choice "Research Organization and Academic Writing" (for 
the second-year students).

Cooperation with the University of Northumbria went on after the visit to the United Kingdom. Thus, in April 2019, VNTU hosted a meeting of academics with a representative of the British University Baranchenko. Since the main carriers of the values of corporate culture, the source of samples of academic writing are academics, a colleague conducted a workshop with VNTU academics. Baranchenko dwelled on the common problems of Ukrainian and British universities such as the nature and mechanisms for preventing academic plagiarism. He began a discussion on research integrity, and gave examples of the specific case studies of plagiarism detection procedures in British scientists' research. The publication of scientific papers in professional journals is one of the components for introduction of research integrity. This determined the topic of the next workshop, namely the requirements and editorial policy of international publications. After the meeting with Baranchenko the team proposed to include actions assisting to maintain high ethical standards in research to the planned activities of the Project. The scientific discussion on joint actions with team members contributing to the honest research of young scientists' was supported by the heads of departments.

Taking into account that the comprehensive implementation of policy of academic standards compliance requires monitoring, evaluation and forecast of changes of the state of the established culture of academic integrity, at the third stage of the Project the state of the established culture of academic integrity in the student environment of VNTU was monitored and analysis of outcomes was reported on the Science Council, scientific and methodical council and student self-government body.

The project team members initiated the further process for ensuring, preserving and promoting the values of academic integrity and academic relationships after the completion of the VNTU team's participation in the Program. United by the project representatives of the university community, namely managers, academics, active students, employees of the scientific and technical library of VNTU, representatives of the Center for Quality Assurance of Education of VNTU and the Psychological Support Service formed the critical mass able to change the environment, generate new ideas to create an environment for non-acceptance of violations of academic integrity. Members of the Project team are included in the group formed in VNTU to promote academic integrity, whose activities will be related to the overall coordination of policies and mechanisms ensuring academic integrity, ethics of academic relations (teaching, learning, research) and already defined areas of activity (establishment of value orientations and motivation for compliance with the principles of academic integrity, development of regulative documents and information support for the implementation of the principles of academic integrity, modernization of the organizational structure of the university, update of the content of education and academics' professional qualification improvement).

As the activities to ensure building a culture of academic integrity at VNTU 
had been lasting for two years, one more study (for comparing with 2018 survey) on the students' attitude to academic integrity was held. There were 390 respondents in 2020 survey (Table 2).

Analysis of students' responses, concerning the motives for studying at the

Table 2. Comparative analysis of students' attitudes to issues of academic integrity in VNTU (number of students' answers, \%).

\begin{tabular}{clcc}
\hline \multirow{2}{*}{ 1. The purpose of study at the university } & \multicolumn{2}{c}{ Year } \\
\cline { 3 - 4 } & Acquiring a professional knowledge & 2018 & 2020 \\
\hline 2 & Getting a diploma & 56.2 & 70.1 \\
3 & Receiving a scholarship & 29.0 & 22.7 \\
4 & Obtaining a parental approval & 6.5 & 0.7 \\
5 & Difficult to answer & 6.3 & 2.1 \\
\hline
\end{tabular}

2. Use of dishonest practices by students when taking tests/exams

I prepare cheat sheets using lecture material or other material provided by a teacher

2 I use Internet while answering the questions

3 I prepare cheat sheets, "bombs" using Internet resources

$4.9 \quad 2.4$

4 I cheat from other students

$6.4 \quad 4.5$

5 I ask a teacher or administration to give me a grade for services or remuneration

6 I use technical devices for consultations and writing down the answers being dictated

7 I buy ready-made cheat sheets

0.9

8 I do not use dishonest practices

23.0

3. The main reasons for spreading plagiarism in the student environment at VNTU

\begin{tabular}{llcc}
\hline & $\begin{array}{l}\text { The need to do a great number of written tasks during the } \\
\text { academic semester }\end{array}$ & 32.1 & 31.9 \\
2 & Lack of practical application for learning outcomes & 15.1 & 14.9 \\
3 & Lack of clear requirements for assessing the originality of texts & 10.1 & 10.0 \\
4 & Neutral teachers' attitude to plagiarism & 9.9 & 9.8 \\
$\quad \begin{array}{l}\text { The habit of using plagiarism have been formed before entering } \\
\text { the university }\end{array}$ & 21.2 & 20.0 \\
6 & Difficult to answer & - & 1.9 \\
7 & Low level of teachers' professionalism & 11.6 & 11.5
\end{tabular}

4. Cases of corruption: do you happen to receive grades for services and/or money at your faculty?

$\begin{array}{llll}1 & \text { yes, such cases do happen } & 20.2 & 16.5 \\ 2 & \text { it is hard to say for sure } & 42.3 & 30.6 \\ 3 & \text { no, it is impossible } & 37.5 & 52.9\end{array}$


university, showed that the number of students considering knowledge to be a factor that will contribute to their professional success has increased (by 14\%). Consider this an important result, because the focus on the importance of knowledge, education, erudition as a value, will stimulate active responsible learning.

It is important to state an increase in the number of students not using dishonest practices in 2020 survey (38.8\%) comparing with 2018 survey $(23.0 \%)$. Thus, a system of trainings on academic integrity for students, meetings with successful VNTU graduates and representatives of the business elite of the region, personal conversations with students helped to increase motivation for learning, more conscious and responsible students' attitude to independent, systematic acquisition of knowledge.

There are numerous reasons for the violation of academic integrity, which vary based off of situation and institution. Studies conducted by different researchers in the United States of America reveal that students engage in academically dishonest practices due to performance-the need to get better grades (Jones, 2011); ignorance (Jocoy \& DiBiase, 2006); in pursue of a good job (McCabe, Trevino, \& Butterfield, 2001), etc. Undoubtedly academic dishonesty remains an important issue in both Ukraine and the United States. However, academic integrity violations in American universities are less frequent than in Ukrainian ones. In research (Stephens et al., 2010), comparing academic behaviour of students from one university in the USA and one in Ukraine, 378 students-189 from each university-were asked about different forms of academic dishonesty they were involved during their studies. The results showed a significant difference between American and Ukrainian students as for all forms of academic integrity violations: twice as many interviewed Ukrainian students admitted to cheating on home assignments, accounting for $72 \%$ in comparison to $30.7 \%$ of interviewed American students; almost five times more Ukrainian students admitted to plagiarising from the Internet- $77.7 \%$ of Ukrainians as opposed to $16.5 \%$ of Americans; and cheating on exams at university was more than seven times higher-81.9\% of Ukrainians admitted to engaging in the practice as opposed to $11.1 \%$ of Americans.

The students' VNTU opinions about the main reason for spreading plagiarism, namely, the need to do a great number of written tasks during the academic semester, remains unchanged. There was a slight decrease in the number of students stating earlier (2018) the lack of practical application for learning outcomes (from $15.1 \%$ to $14.9 \%$ ), the neutral teachers' attitude to the manifestations of plagiarism (from 9.9\% to 9.8\%), low level of teachers' professionalism (from $21.2 \%$ to $20.0 \%$ ). The results of the survey showed that further work to improve VNTU academics' skills, resulting in their awareness of the relationship between higher education quality and academic integrity, mastery of modern educational teaching technologies, updating the content of education, in particular, an increase of practically oriented tasks have to remain an important priority in the process of building a culture of academic integrity in the student environment. 
During the project implementation the attention of the VNTU administration to cases of corruption has increased, resulting in fewer manifestations of corruption in the educational activities. Thus, if in 2018 the absence of corruption at the faculty was noted by $37.5 \%$ of students, in 2020 it is already noted by $52.9 \%$ of students. On the one hand, there is a clear positive trend in the results of fighting corruption in the educational activities, but, on the other hand, many students (almost half) face manifestations of corruption. Therefore, the problem of fighting corruption remains very relevant.

The Academic Integrity Promotion Group has identified further concrete steps to promote the idea of the importance of creating a virtuous university environment.

Since every year the first-year students are enrolled to study at the university, events aimed at forming value orientations and motivation to follow the principles of academic integrity at the very beginning of education are planned to be held, namely: educational work on mastering the values of academic integrity; tools to prevent academic plagiarism; motivating students to honest intellectual work; providing consulting services for establishing a culture of academic integrity.

Development of normative documents and information support for academic integrity policy will include development, discussion, implementation, improvement of normative documents describing the system and mechanisms of encouragement for observance of academic integrity principles (Declaration on academic integrity of VNTU students, detailed description of prevention procedure, detection of academic plagiarism in educational, scientific works and course/diploma projects/works) and impose sanction actions in case of identified violations; creation of an information base (site/rubric "Academic Integrity") and materials for popularization of the principles of academic integrity; development of criteria for the competition of written works, social videos for the award of conscientious students.

Modernization of the organizational structure of the university should provide creation of the Commission on Academic Integrity in VNTU including a representative of the university student self-government scientific department responsible for observance of academic integrity by students.

The development of academics' professional and pedagogical competence should be realized due to the constant updating the content of the program for advanced training and its individualization.

Thus, the implementation of the project "Building a culture of academic integrity in the student environment in VNTU" contributed to the following: popularization of the values of academic integrity; involvement of the active academics and students in the establishment of academic relation ethics; actualization of discussion on high integrity research. The project has been a catalyst for a paradigm shift in university management, enhancing the principles of partnership and distributed responsibility, openness, transparency and accountability; contributed to strengthening the sense of unity, cohesion in the institutional devel- 
opment of the university not only among team members, but also among active members of the university community.

\section{Conclusion and Implication}

Having analyzed the experience of the project "Building a culture of academic integrity in the student environment" run in Vinnytsia National Technical University it can be stated:

1) Ensuring the strategic priorities of VNTU development has determined the urgency of the problem for adherence to the principles of academic integrity in the student environment. To solve this problem, in 2017 the university developed a project "Building a culture of academic integrity in the student environment" and created a team to implement it. The main goals of the Project were as follows: establishing moral and ethical values in students; providing a wide range of motivation for students to honest and responsible learning; changing the students' and academics' attitude to violations of the principles of academic integrity. The decisive role in the implementation of the Project was played by the participation of the VNTU team led by the Rector in the Program of Leadership Development of Ukrainian Universities. The sessions and trainings formed the team members' clear understanding in the need to strengthen horizontal ties at the university to establish a culture of academic integrity in the student environment; broad involvement of external as well as internal stakeholders to the management; the importance of student participation in discussions of current university issues; focus on academics' professional and personal development. This allowed gradual involving of the university community's active representatives in the implementation of the Project, expanding the list of external stakeholders and identifying opportunities for cooperation with them; intensifying and "deforming" student self-government bodies' activity, identifying student leaders able to promote the values of academic integrity; concentrating efforts organizing advanced trainings for academics to master modern methods of teaching and practices to prevent infringements of principles of academic integrity; creating a Training Center as a modern subject-spatial environment stimulating the use of interactive technologies both in the students' educational process and in the academics' professional development.

A very important achievement of the team members' participation in the sessions of the Program was the acquaintance and testing key tools for management of strategic university changes, which will allow them to be used in the implementation of other university projects.

Within the framework of the Program, team members also had the opportunity to establish a network of contacts with representatives of other HEIs of Ukraine for the exchange of knowledge and information in order to further scale the experience in building a culture of academic integrity. The team members' visit to the University of Northumbria was of great importance, during which the experience of ensuring the principles of academic integrity in the context of 
multicultural education was learned.

2) The main results of the Project were as following: the content of education for the first and second year students was updated making it possible to focus on value orientations, motivation of students to good education; expanded and deepened cooperation with internal stakeholders (administration of faculties, student self-government bodies, employees of the Main Center for Organization and Methodological Support of Training, Center for Social Communications and Leadership, Scientific and Technical Library) and with external ones, such as (Department of Information Technologies of Vinnytsia City Council, Institute of Urban Development, non-governmental organization (NGO) HUB City of Contents, NGO Public Initiatives of Ukraine); modernized the organizational structure of the university (created a sector of practices of academic integrity and staff development, a group to promote academic integrity, elected an ombudsman for the students' rights of VNTU); Training Center has been established, which allows holding interactive activities aimed at establishing partnerships of research and teaching staff with students, teaching the rhetoric of dialogue, the essence and principles of team leadership; a program of advanced training was launched, which is aimed at mastering modern teaching technologies by academics, mastering the tools for forming students' competencies of creativity, critical thinking, cooperation and communication skills.

3) Further steps for developing a culture of academic integrity in the university involve the following:

- continuing by the Academic Integrity Support Group, the Academic Integrity Advisory Center, the Academic Integrity and Personnel Development Practices Sector (in cooperation with the VNTU Center for Quality Assurance in Education, the Center for Organization and Methodological Support of Training, the Center for Social Communications and Leadership, the Scientific and Technical Library Sociological Laboratory and the Service for Psychological Support of Students) educational and advocacy work, which will promote the dissemination of provisions on policies, standards and procedures for adhering to a culture of academic integrity; training speakers on this issue representing student self-government body;

- updating the content of the "Regulations on the academic integrity of students, research and teaching staff" in terms of describing the mechanisms for monitoring compliance with academic integrity, which should include mandatory verification of written works to identify textual and other borrowings without proper references, peer review of scientific texts before publication, an anonymous survey of students on the presence/absence of violations of academic integrity. This Regulation should also describe effective, clear and transparent procedures for responding and prosecuting violations of academic integrity;

- developing and approving methodical recommendations for administrative staff and academics on the use of tools introducing and supporting the principles of academic integrity (at the level of faculty, department, study group); 
instructional materials for teaching and supporting VNTU staff to promote the development of academic integrity and prevent its violations;

- appealing with initiatives:

- to the Institute of Master's, Postgraduate and Doctoral Studies on the establishment of the Young Scientists' Council in VNTU, enabling to promote academic research integrity;

- to stakeholders (former graduates) on the establishment of the VNTU Alumni Association in order to deepen cooperation providing the best graduates with the first job.

The experience of the project "Building a culture of academic integrity in the student environment" allowed offering the following recommendations for the HEIs:

- provide in the educational process the possibility for students to learn about the concept of "academic integrity", types of its violations and responsibility in case of their detection. Keep in mind that building a culture of academic integrity in the student environment is a long-term process involving not only delineation, fixation, but also conscious and free acceptance of its principles by all members of the educational process. Academic norms and principles (through the process of internalization) should become a part of the internal structure of consciousness of each participant of the educational process as a result of the individual's mastery of what was originally an external requirement for him;

- emphasize that the value component of the corporate culture of the university should be the principles of academic integrity (fairness, trust, respect, honesty, responsibility, courage), which provide high moral standards and are a guarantee of quality education in HEI. Key values, beliefs and norms of behavior, which are perceived as mandatory for understanding and acceptance by all members of the university community, create a sense of unity and commitment to the common mission of training highly qualified professionals;

- take into account that process of building a culture of academic integrity in the student environment is cyclical, requires systematic implementation, is regulated and provided by constant monitoring of results. For a transparent and open assessment of the state of established culture of academic integrity, it is advisable to hear the annual report at the University Academic Council and publish it on the HEI website;

- emphasize that an important condition for establishing principles of academic integrity is the involvement of all participants of the educational process. A special role in the process of building a culture of academic integrity in the student environment should be played by student self-government body promoting the idea that academic integrity is a tool for quality higher education, and further success in professional activities and responsible citizenship.

The subject for further research should be the practice of implementing poli- 
cies and mechanisms to ensure academic integrity in the universities of the leading countries of education.

\section{Conflicts of Interest}

The authors declare no conflicts of interest regarding the publication of this paper.

\section{References}

Altbach, P., Reisberg, L., \& Rumbley, L. (2009). Trends in Global Higher Education: Tracking an Academic Revolution. A Report Prepared for the UNESCO 2009 World Conference on Higher Education. http://unesdoc.unesco.org/ark:/48223/pf0000183168

Becher, T., \& Trowler, P. R. (2001). Academic Tribes and Territories: Intellectual Enquiry and the Cultures of Disciplines (2nd ed.). Buckingham: Open University Press/SRHE.

Fishman, T. (Ed.) (2013). The Fundamental Values of Academic Integrity (2nd ed.). https://academicintegrity.org/wp-content/uploads/2017/12/Fundamental-Values-2014. $\underline{\mathrm{pdf}}$

Gallant, T. (2012). Twenty Years of Academic Integrity: Top Articles \& Book Chapters 1992-2012.

https://academicintegrity.org/wpcontent/uploads/2017/12/462c19_88fa30a3dcff420bb6 b3ea84697d8b1b.pdf

Hrynevych, L. (2014). Peredmova. In Imperativ yakosti: vchimosya tsinuvati i otsinyuvati vischu osvitu [Introduction in the Imperative of Quality: We Learn to Value and Evaluate Higher Education] (p.12). LvIv: Manuskript. (In Ukrainian)

Jocoy, C., \& DiBiase, D. (2006). Plagiarism by Adult Learners Online: A Case Study in Detection and Remediation. The International Review of Research in Open and Distance Learning, 7, 1-17. https://doi.org/10.19173/irrodl.v7i1.242

Jones, D. (2011). Academic Dishonesty: Are More Students Cheating? Business Communication Quarterly, 74, 141-150. https://doi.org/10.1177/1080569911404059

Kalashnikova, S., \& Orzhel, O. (2019). University Leadership Development: Lessons from Ukraine. University and Leadership, 2, 133-143.

https://ul-journal.org/index.php/journal/article/view/104/97

Kalashnikova, S., \& Prokhor, I. (2017). Prohrama rozvytku liderskoho potentsialu universytetiv: vid idei do realizatsii. Filosofskyi analiz praktyky doslidnytskoho vriaduvannia v universytetakh Velykoi Brytanii [Universities Leadership Development Program: From Idea to Realization. A Philosophical Analysis of the Practice of Research Governance in UK Universities]. Universytet i liderstvo, 1, 1-10. (In Ukrainian) https://ul-journal.org/index.php/journal/article/view/65/65

McCabe, D., Trevino, L., \& Butterfield, K. (2001). Cheating in Academic Institutions: A Decade of Research. Ethics \& Behavior, 11, 219-232.

https://doi.org/10.1207/S15327019EB1103_2

Schleicher, A. (2018). World Class: How to Build a 21st-Century School System, Strong Performers and Successful Reformers in Education. Paris: OECD Publishing. https://doi.org/10.1787/9789264300002-en

Slobodianiuk, O. (2018). Rol naukovo-pedahohichnoho kolektyvu u formuvanni kultury akademichnoi dobrochesnosti studentiv. [The Role of the Scientific and Pedagogical Team in Shaping the Culture of Academic Integrity of Students.] Scientifical Journals of Vinnytsia National Technical University, 65, 130-134. (In Ukrainian) 
Stephens, J., Romakin, V., \& Yukhymenko, M. (2010). Academic Motivation and Misconduct in Two Cultures: A Comparative Analysis of US and Ukrainian Undergraduates. The International Journal for Educational Integrity, 6, 47-60.

https://doi.org/10.21913/IJEI.v6i1.674

The Bucharest Declaration Concerning Ethical Values and Principles for Higher Education in the Europe Region (2004).

https://www.tandfonline.com/doi/abs/10.1080/03797720500083922?journalCode=chee 20

Ukraine Higher Education Leadership Development Programme: Impact Report (2019). Prohrama rozvytku liderskoho potentsialu universytetiv Ukrainy: Otsinka vplyvu. (In Ukrainian)

http://www.britishcouncil.org.ua/sites/default/files/evalution_of_impact_eng.pdf 